\title{
Processing and microstructure of non-oxide ceramic fibres
}

\author{
V S R MURTHY \\ Department of Metallurgical Engineering, Indian Institute of Technology, Kanpur 208016 , \\ India \\ MS received 29 October 1992

\begin{abstract}
Research and development efforts on high-temperature, oxidation-resistant fibres have increased over the past decade due to the demand for light-weight, stiff and strong composite materials in aerospace applications. Varieties of 'high-performance', continuous, non-oxide fibres with low-density, high tensile strength and tensile modulus have been developed either from organic precursors or via chemical vapour deposition for fabrication of ceramic matrix composites. Fibres derived from polymer precursors (e.g. Nicalon, Tyranno, HPZ) are small in diameter (compared to CVD monofilaments) and are ideally suited for ceramic composites. Processing. microstructural stability and mechanical properties of these newly developed $\mathrm{SiC}$ and $\mathrm{Si}_{3} \mathrm{~N}_{4}$ base fibres are briefly reviewed in this paper.
\end{abstract}

Keywords. $\mathrm{SiC} ; \mathrm{Si}_{3} \mathrm{~N}_{4} ;$ composites; organic/polymer precursors; curing; pyrolysis; chemical vapour deposition; microstructure; mechanical properties.

\section{Introduction}

Monolithic structural ceramics such as silicon carbide, silicon nitride and sialons are inherently brittle, and are highly sensitive to processing and surface (Griffith) flaws. To overcome the inherent brittleness, there has been intensive research activity for the development of 'highly-reliable' and 'damage-tolerant' ceramic matrix composites (CMCs) in the past decade. The first approach adopted was dispersion of particles, platelets or whiskers in a ceramic matrix with the objective of increasing fracture toughness $\left(K_{c}\right)$ two to three times of the matrix value. In these composites, apart from second phase morphology, thermal expansion mismatch and dispersoid-matrix interface, toughening mechanisms such as crack-deflection, crack-bridging and pull-out play an important role in the enhancement of fracture toughness.

The second approach is based on incorporation of high-strength, high-modulus, semi-continuous ceramic fibres in a brittle matrix, to give a 'graceful' failure in a service overload situation by transferring the load to the fibre via a weakly bonded fibre-matrix interface. In fibre reinforced ceramic matrix composites (FRCMCs), the pull-out of fibres in the crack-wake makes an important contribution to the enhancement of toughness. The pull-out is influenced by the properties of the fibres and by the sliding resistance of the interface. Parameters which dominate the micromechanical behaviour of interfaces are thermal expansion mismatch strain $(\varepsilon)$, the critical strain energy release rate (fracture energy) for the interface relative to that for the fibre $\left(G_{i} / G_{f}\right)$, and shear resistance of the interface $(\tau)$, after debonding. From the experimental and theoretical work, the following criteria have emerged. $G_{i} / G_{f} \leqslant 1 / 4 ; 2 \leqslant \tau \leqslant 40$, $\varepsilon 3 \times 10^{-3}$ (Cao et al 1990; Evans 1990). An in situ carbon-rich layer formed in silicate matrices or a pre-synthesized layer deposited on the fibres prior to fabrication fulfils the above prerequisites.

For FRCMC fabrication, high-modulus oxidation resistant fibres with smalldiameter are ideal. Small-diameter fibres are easily weavable to produce net-shape 
fibre preforms that are subsequently infiltrated by a matrix. The high volume fraction of small-diameter fibres not only reduces the risk of introducing process-related flaws but also ensures that a sufficient number of fibres bridge the matrix microcracks, thereby greater applied strains for further matrix crack propagation. Another advantage of using a small-diameter fibre is that the fibre length required for full fibre-matrix load transfer is also small (Dicarlo 1989). Additionally, reinforcing fibres should be capable of retaining the structure, stiffness and strength under processing and service conditions i.e. $>1000^{\circ} \mathrm{C}$. Keeping these in view, a wide range of oxide and non-oxide ceramic fibres suitable for ceramic matrix reinforcement have been developed.

Carbon fibres offer a wide range of mechanical properties. However, they exhibit poor oxidation resistance. Although oxide fibres (e.g. $\left.\mathrm{Al}_{2} \mathrm{O}_{3}\right)$ are capable of withstanding higher temperatures, reactivity with silicate matrices and poor creep properties discouraged their use in high temperature ceramic composites. Fibres based on the compounds of $\mathrm{SiC}$ and $\mathrm{Si}_{3} \mathrm{~N}_{4}$ have received greater attention due to their improved stability in oxidizing conditions and reduced reactivity during processing. Among various non-oxide fibres, the most developed systems are silicon carbide and silicon nitride. Compared to monofilaments, fibres developed from polymer base precursors are fine in diameter $(8-15 \mu \mathrm{m})$ and are ideally suited for $\mathrm{CMC}$ fabrication. The production methods, microstructure and mechanical properties of various non-oxide fibres are reviewed in the following sections.

\section{Fibres derived from organic precursors}

Although the conversion of organometallic polymers to covalent solids was known for a long time (Chantrell and Popper 1965; Popper 1967), only in the recent past, this process has gained prominence for the production of fine ceramic powders, coatings and fibres (Yajima 1980; Rice 1983; Wynne and Rice 1984; Wei et al 1984). Some potential advantages of preparing inorganic materials via organic precursors are (i) improved compositional homogeneity in the final product due to mixing of elemental components on the molecular and atomic levels, (ii) high-purity ceramic products with uniform non-crystalline/microcrystalline microstructures, (iii) ability to produce high surface area powder of controlled morphology, (iv) preparation of refractory ceramics at exceptionally low temperatures and (v) some compositions which cannot be obtained in traditional route can be prepared using organometallic polymers. Precursor materials used for the development of ceramic fibres/coatings should possess properties such as high molecular weight to reduce volatilization, tractability (meltability, malleability or solubility) to form any desired shape before final curing, polymeric structure that is branched or containing cages/rings to decrease the polymer skeleton degradation, presence of latent chemical reactivity for thermo-setting/curing and low organic functional group content to increase ceramic yield and low residual free carbon/carbides.

Carbon fibres with high tensile strength were successfully produced by controlled processing of polyacrylonitrile (PAN) precursor (Morley 1987). A similar approach led to the development of fibres with constitution of Si and $\mathrm{C}$ or N. In particular, polysilane or polycarbosilane (PCS) precursors to $\mathrm{SiC}$ and polysilazane precursors to silicon nitride are emerging as potential starting materials for the development of high-strength, high-modulus continuous fibres. 


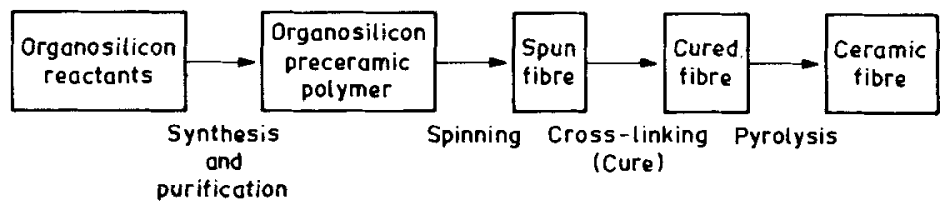

Figure 1. Various steps involved in the preparation of ceramic fibres from polymer precursors.

For obtaining continuous ceramic fibres, a preceramic organosilicon polymer is synthesized, purified, spun and cross-linked (curing and pyrolysis) to obtain an inorganic microcrystalline structure with good mechanical properties (figure 1). Each step is dictated by several important factors that will affect final fibre properties. Utmost care has to be taken in purifying the polymer to remove impurities and particulates, which can become the strength-limiting critical flaws in the ceramic fibre. The final properties also depend on the type of spinning viz. wet, dry or melt spinning (Lipowitz 1991). Fibres must be well cured to prevent any inter-fibre fusion during process. Fibre tows, consisting of several hundred individual fine fibres are treated with a sizing agent to minimize abrasion damage during curing (chemical, thermal or irradiation) process. In curing, fibre is converted to a highly cross-linked, infusible material. Finally, by pyrolysing, volatile materials are lost and an inorganic ceramic material is developed.

\subsection{Polymer precursors for SiC ceramic fibres}

2.1a Polycarbosilane (PCS): An extensive work carried out by Yajima and coworkers on the development of $\mathrm{SiC}$ fibres has revolutionized the field of composites. Various polycarbosilane precursors synthesized to obtain better ceramic yield and tensile properties are listed in table 1 . At infancy stages, polycarbosilane was prepared from dodecamethylcyclohexasilane (PC-D) (figure 2). This method was technically difficult, expensive and time-consuming and therefore, in an improved method, polycarbosilane was derived from polydimethylsilane (PC-A). Later this process was also abandoned due to usage of an autoclave. Subsequently another method was developed by polymerizing polydimethylsilane under nitrogen flow (PC-N). Further, this process can also be accelerated by small additions of polyborodiphenylsiloxane (PC-B). PC-N and PC-B fibres (table 1 ) (figure 2) are now being manufactured by Nippon Carbon Co., Tokyo, under the trade name 'Nicalon'. These fibres are currently available for the development of polymer, metal and ceramic matrix composites.

2.1b Polysilanes: Methylchloropolysilane is synthesized by redistribution of $\mathrm{Si}-\mathrm{Cl}$ and Si-Si bonds. Mixed disilanes are catalytically rearranged with tetrabutyl phosphonium chloride to produce methylchloropolysilane preceramic polymer (Baney and Gaul 1982; Baney 1984).

2.1c Polysilastyrene: Polysilastyrene is developed from a combination of dimethyldichlorosilane and phenylmethyldichlorosilane with the addition of sodium metal in a hydrocarbon solvent such as toluene (Mazdiyani et al 1978; West et al 1983; West 1984). Absorption of an ultraviolet light $(300-350 \mathrm{~nm})$ by solid polysilastyrene 
Table 1. Organic precursors for $\mathrm{SiC}$ ceramic fibres.

\begin{tabular}{|c|c|c|}
\hline Notation & PCS is obtained from any other precursor & References \\
\hline PC-TMS & $\begin{array}{l}\text { Tetramethylsilane (TMS) by heat condensation } \\
\text { at } 700^{\circ} \mathrm{C}\end{array}$ & Fritz et al (1965) \\
\hline PC-D & $\begin{array}{l}\text { Dodecamethylcyclohexasilane (DMCHS) which } \\
\text { is obtained by conversion of dimethyldichloro- } \\
\text { silane (DMDCS) with the addition of lithium }\end{array}$ & Yajima et al $(1975,1976 a)$ \\
\hline PC-A & $\begin{array}{l}\text { Polydimethylsilane (PDS) which is derived } \\
\text { from dimethyldichlorosilane (DMDCS) using } \\
\text { autoclave }\end{array}$ & $\begin{array}{l}\text { Yajima et al (1976b), Yajima (1983), } \\
\text { Hasegawa and Okamura (1986), } \\
\text { Hasegawa et al (1980) }\end{array}$ \\
\hline $\mathrm{PC}-\mathrm{N}$ & $\begin{array}{l}\text { Polydimethylsilane (PCS) using reflex condenser } \\
\text { (without autoclave) }\end{array}$ & Yajima et al (1976c, 1978b) \\
\hline \multirow[t]{2}{*}{ PC-B } & Polydimethylsilane (PDS); additionally & Yajima et al (1977a,b, 1978a) \\
\hline & Polyborodiphenylsiloxane (PBDPSO) is added & Ichikawa et al (1986) \\
\hline- & $\begin{array}{l}\text { Polysilastyrene (dimethyl dichlorosilane }+ \\
\text { phenylmethyldichlorosilane) }\end{array}$ & West (1984), West et al (1983) \\
\hline - & $\begin{array}{l}\text { Silicon - carbon bond forming reactions of } \\
\text { vinylic or chloromethyl silanes }\end{array}$ & Schilling et al (1983) \\
\hline - & $\begin{array}{l}\text { Dehydrocoupling of } \mathrm{MeSiH}_{3} \text { to obtain } \\
\text { polymethylsilane }\end{array}$ & Zhang et al (1991) \\
\hline- & Polysilanes & Baney (1984), Carlsson et al (1990) \\
\hline- & Commercial polycarbosilane & Soraru et al $(1990)$ \\
\hline
\end{tabular}

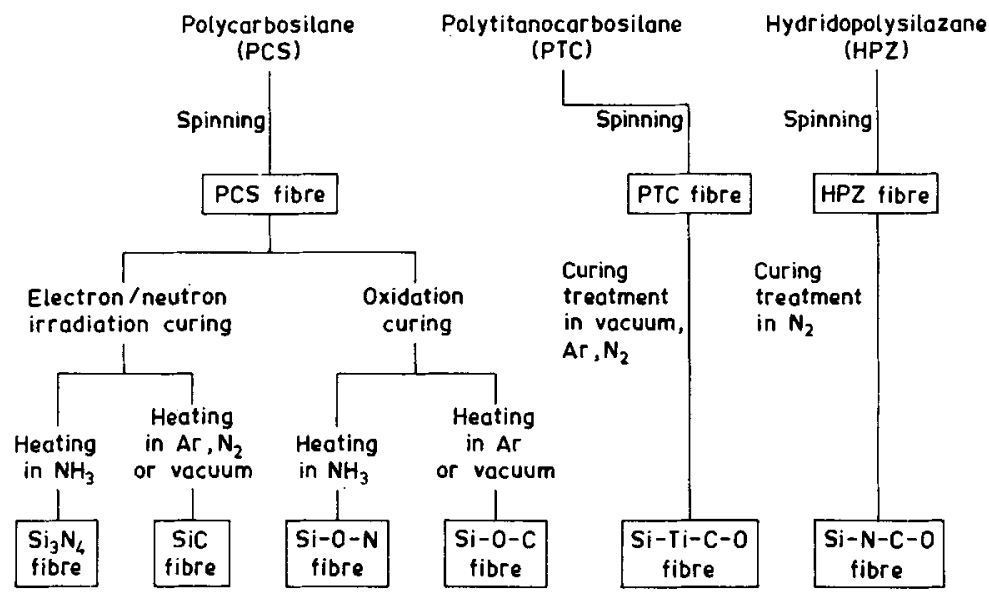

Figure 2. Processing routes for selected non-oxide ceramic fibres obtained from various polymer precursors.

in an inert atmosphere leads to cross-linking by decrease in weight and the polymer becomes rigid.

2.1d Polytitanocarbosilane (PTC): Polytitanocarbosilane is synthesized using a mixture of polydimethylsilane, polyborodiphenylsiloxane and titanium alkoxide (Yajima et al 1981; Song et al 1988; Yamamura et al 1988) (figure 2). They are heated to $340^{\circ} \mathrm{C}$ under nitrogen atmosphere for $12 \mathrm{~h}$ to obtain polytitanocarbosilane precursor. The polymer is concentrated and $\mathrm{Si}-\mathrm{Ti}-\mathrm{C}-\mathrm{O}$ fibre is produced by melt-spinning at 
$\sim 270^{\circ} \mathrm{C}$. During the above process, the cleavage of $\mathrm{Si}-\mathrm{Si}$ bonds in polydimethylsilane, formation of $\mathrm{Si}-\mathrm{H}$ and $\mathrm{Si}-\mathrm{CH}_{2}-\mathrm{Si}$ bonds, condensation of $\mathrm{Si}-\mathrm{H}$ bonds and cross-linking by the titanium compound occur simultaneously (Yamamura 1984). Alternatively, polytitanocarbosilane can also be obtained by the reaction of polycarbosilane (PC-B in table 1) with titanium tetrabutoxide at $\sim 200^{\circ} \mathrm{C}$ (Okamura et al 1985). Fibres derived from PTC are currently produced by Ube Industries Ltd., Tokyo, under the trade name 'Tyranno'.

\subsection{Polymer precursors for $\mathrm{Si}_{3} \mathrm{~N}_{4}$ ceramic fibres}

Silicon (oxy) nitride fibres are prepared from a wide variety of precursors such as polycarbosilane, poly (di) silazane, polysilane, etc. (table 2). The common method for silazane synthesis is the ammonolysis of halosilanes. The presence of $\mathrm{Si}-\mathrm{CH}_{3}$ groups in polysilazanes consistently results in small proportion of $\mathrm{SiC}$ along with $\mathrm{Si}_{3} \mathrm{~N}_{4}$ after pyrolysis (Penn et al 1982). Similarly, oxygen is induced in the nitridation of polycarbosilane during oxidation curing (Okamura et al 1988b). The fibres produced by fibermic (Rhone-Poulenc, France) or HPZ (Dow Corning, USA) contain small concentrations of oxygen and carbon. Relatively oxygen/carbon free fibres with $\mathrm{Si}_{3} \mathrm{~N}_{4}$ constitution can be obtained by electron/neutron irradiation curing of polycarbosilanes (Okamura et al 1987a).

\subsection{Conversion of polymer precursors to ceramic fibre}

2.3a Oxidation curing and pyrolysis: Polycarbosilane is melt spun into fibres at $290-310^{\circ} \mathrm{C}$ in a nitrogen atmosphere. These fibres are oxidation-cured at $190^{\circ} \mathrm{C}$ in air to cross-link polycarbosilane molecules; depending on curing conditions, properties of SiC fibres vary (Ichikawa et al 1987). Using various techniques such as IR spectros-

Table 2. Organic precursors for $\mathrm{Si}_{3} \mathrm{~N}_{4}$ base ceramic fibres

\begin{tabular}{|c|c|}
\hline Investigators & Precursor/Preparative method \\
\hline Verbeek $(1974)$ & $\begin{array}{l}\text { Polysilazanes obtained from alkylchlorosilane } \\
\text { and alkylamines }\end{array}$ \\
\hline Penn et al (1982) & $\begin{array}{l}\text { Polysilazane prepared from tris ( } \mathrm{N} \text {-methylamino) } \\
\text { methylsilane }\end{array}$ \\
\hline Okamura (1987), Okamura et al (1988) & Nitridation of polycarbosilane* \\
\hline Baney (1984) & $\begin{array}{l}\text { Polydisilylazane by reaction of mixed disilanes } \\
\text { with hexamethyldisilazane }\end{array}$ \\
\hline Seyferth and Wiseman (1984) & $\begin{array}{l}\text { Polysilazane by the reaction of chlorosilane } \\
\text { with ammonia and dichloromethane }\end{array}$ \\
\hline Wills et al (1983) & Polysilanes/polysilazanes \\
\hline Legrow et al (1987) & $\begin{array}{l}\text { Hydridopolysilazane by the reaction of trichloro- } \\
\text { silane and hexamethyldisilazane }\end{array}$ \\
\hline Blum et al (1989) & Various polysilazanes \\
\hline Schmidt et al (1990) & Vinylic polysilane \\
\hline Yokoyama et al (1991) & $\begin{array}{l}\text { Perhydropolysilazane by ammonolysis of chloro- } \\
\text { silane } \cdot 2 \text { pyridine }\end{array}$ \\
\hline
\end{tabular}

*Produced by Toa Nenyo Kogyo K. K., Tokyo, Japan. 


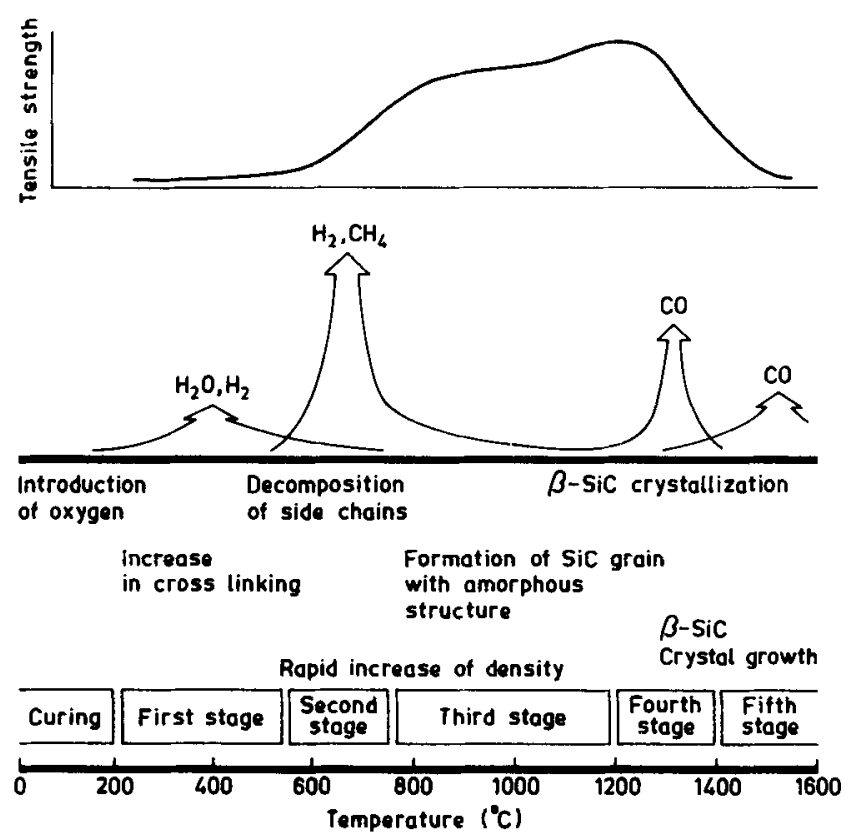

Figure 3. Gas evolution and tensile strength during conversion of thermal oxidation curing of polycarbosilane (after Okamura 1987; Hasegawa and Okamura 1983).

copy, UV, X-ray, Raman spectroscopy, magic angle spinning nuclear magnetic resonance (MAS-NMR) spectroscopy etc the following steps are identified in conversion of polycarbosilane to SiC fibre (Hasegawa and Okamura 1983; Taki et al 1989):

(I) The weight loss due to evaporation of low molecular weight components and increment in the molecular weight (figure 3 ).

(II) Molecular weight increases by dehydrogenation and dehydrocarbonation condensation.

(III) Side chain decomposition by dehydrogenation and demethanation and the beginning of the inorganic structure starting with the formation of $\mathrm{Si}-\mathrm{C}$ and $\mathrm{C}-\mathrm{C}$ bonds.

(IV) Formation of amorphous SiC.

(V) Formation of $\beta \mathrm{SiC}$ with further dehydrogenation, the product containing excess carbon and silica.

(VI) Crystal growth of crystalline $\beta \mathrm{SiC}$ with a decrease in $\mathrm{Si}-\mathrm{O}$ bonds due to reaction with excess carbon.

In PCS, the transition from amorphous to crystalline occurs approximately at $1000^{\circ} \mathrm{C}$ (Soraru et al 1990) although the crystallization becomes distinctly visible at $1200^{\circ} \mathrm{C}$. Beyond $1200^{\circ} \mathrm{C}$, free carbon dispersed in fibre reacts with oxygen and forms $\mathrm{CO}$. Following various progressive structural readjustments, the fibre gains strength till $1200^{\circ} \mathrm{C}$ and beyond that the strength decreases drastically due to evolution of $\mathrm{CO}$ (figure 3).

Polytitanocarbosilane precursor is more easily spinnable than polycarbosilane. PTC fibre is cured in air at $170^{\circ} \mathrm{C}$ at a heating rate of $150^{\circ} \mathrm{C} / \mathrm{h}$. Cured fibre is finally treated in the temperature range of $800-1500^{\circ} \mathrm{C}$ in a stream of nitrogen to obtain maximum strength. 
Silicon (oxy) nitride fibres are obtained from the nitridation of cured polycarbosilane. On the other hand, silazane fibres are spun in an inert atmosphere (to avoid oxygen) followed by curing treatment in a multi-functional chlorosilane. Finally, fibres are pyrolysed at $1200^{\circ} \mathrm{C}$ in a high pure nitrogen atmosphere (Legrow et al 1987).

$2.3 \mathrm{~b}$ Electron/neutron irradiation curing: At higher temperature $\left(>1300^{\circ} \mathrm{C}\right)$, the tensile strength of $\mathrm{SiC} / \mathrm{Si}_{3} \mathrm{~N}_{4}$ fibres decreases rapidly due to $\mathrm{CO}$ gas evaluation (reaction of $\mathrm{C}$ and $\mathrm{O}$ takes place within the fibre). In order to improve the elevated temperature properties of $\mathrm{SiC} / \mathrm{Si}_{3} \mathrm{~N}_{4}$ fibres, an oxygen-free curing process viz. electron/ neutron irradiation curing has been studied. Doses of electron (15 MGy) or neutron $\left(9 \times 10^{24} \mathrm{n} / \mathrm{m}^{2}\right)$ irradiation increased the density and mechanical properties of the fibre (Okamura et al 1987a, b, 1988a; Matsuzawa et al 1988). The curing mechanism during irradiation process is found to be the breakage of $\mathrm{Si}-\mathrm{H}$ and $\mathrm{C}-\mathrm{H}$ bonds and the formation of $\mathrm{Si}-\mathrm{C}, \mathrm{Si}-\mathrm{Si}$ and $\mathrm{Si}-\mathrm{N}$ bonds (Taki et al 1988).

Radial distribution function (RDF) curves for different SiC fibres subjected to oxidation curing and irradiation treatment are compared in figure $4 \mathrm{a}$. The atomic arrangement of the nearest neighbours remains unchanged while the second nearest neighbour is slightly ordered in irradiated fibres; number of second neighbours are larger in neutron-irradiated SiC fibres. Similarly, in electron-irradiated Si-N fibres, depending on radiation intensity and post heat-treatment, the structure varied from amorphous to $\alpha \mathrm{Si}_{3} \mathrm{~N}_{4}$ (Okamura et al 1988b) (figure $4 \mathrm{~b}$ ).
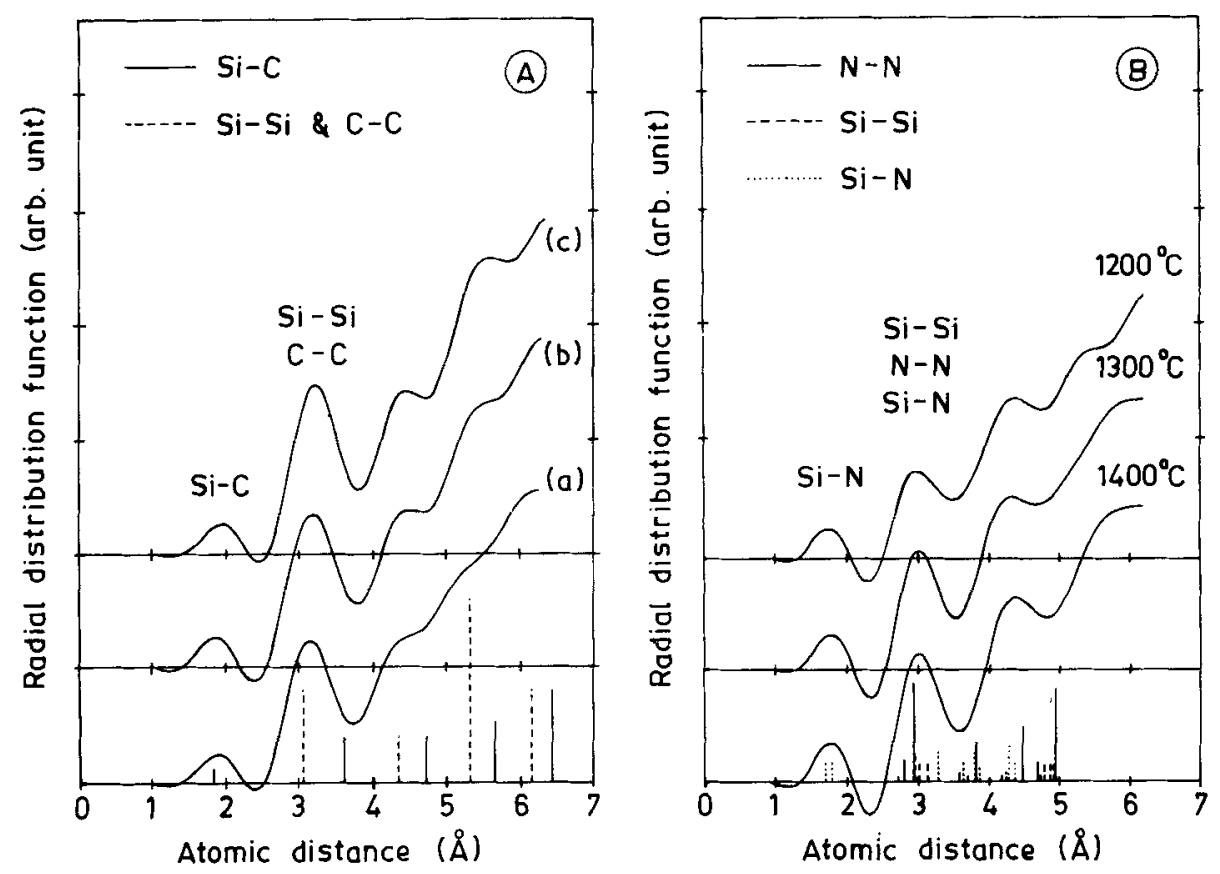

Figure 4. (A) Radial distribution functions of $\mathrm{SiC}$ fibres (a) untreated amorphous $\mathrm{SiC}$ fibre, (b) heat treated at $1200^{\circ} \mathrm{C}$ and (c) neutron irradiated $\left(9 \times 10^{24} \mathrm{n} / \mathrm{m}^{2}\right.$ ) (after Matsuzawa et al 1988) and (B) radial distribution functions of $\mathrm{Si}_{3} \mathrm{~N}_{4}$ fibres obtained by heat treatment of $15 \mathrm{MGy}$ electron irradiation cured fibres at 1200,1300 and $1400^{\circ} \mathrm{C}$ (after Okamura et al $1988 \mathrm{bl}$. 


\subsection{Fibre microstructure}

Among various preceramic precursors synthesized, fibres derived from polycarbosilane, polytitanocarbosilane and hydridopolysilazane have been commercialized (table 3 ). Both Nicalon and Tyranno fibres have similar carbon and silicon levels, but Tyranno additionally contains $2-4 \mathrm{wt} \%$ titanium (figure 5), which is claimed to improve fibre high-temperature properties. Though the fibre chemistry is anticipated to be uniform throughout the structure in these fibres, there are deviations from bulk to the surface. For instance, in Nicalon fibres, oxygen enrichment and Si deficiency have been detected on the fibre surface (Macey et al 1984; Porte and Sartre 1989). Similarly, the HPZ fibres display a surface layer of $\sim 0.5 \mu \mathrm{m}$ thickness which is richer in oxygen as compared to the uniform distribution of $\mathrm{Si}, \mathrm{N}, \mathrm{C}, \mathrm{O}$ in the interior (Sawyer et al 1987).

A large number of characterization techniques (IR, UV, X-ray, electron microscopy, Raman and MAS-NMR spectroscopy, XPS, etc.) have been employed to study chemical bonding and microstructure of polymer derived fibres (Yajima 1985; Legrow et al 1987; Sasaki et al 1987; Song et al 1988; Hasegawa 1989). $\mathrm{SiC}$ and $\mathrm{Si}_{3} \mathrm{~N}_{4}$ base fibres contain $\mathrm{Si}-\mathrm{O}, \mathrm{Si}-\mathrm{C}$ and $\mathrm{Si}-\mathrm{N}$ chemical bonds as revealed by infrared spectroscopy. X-ray photoelectron spectroscopy (XPS) of Nicalon fibre reveals a large Si $2 p$

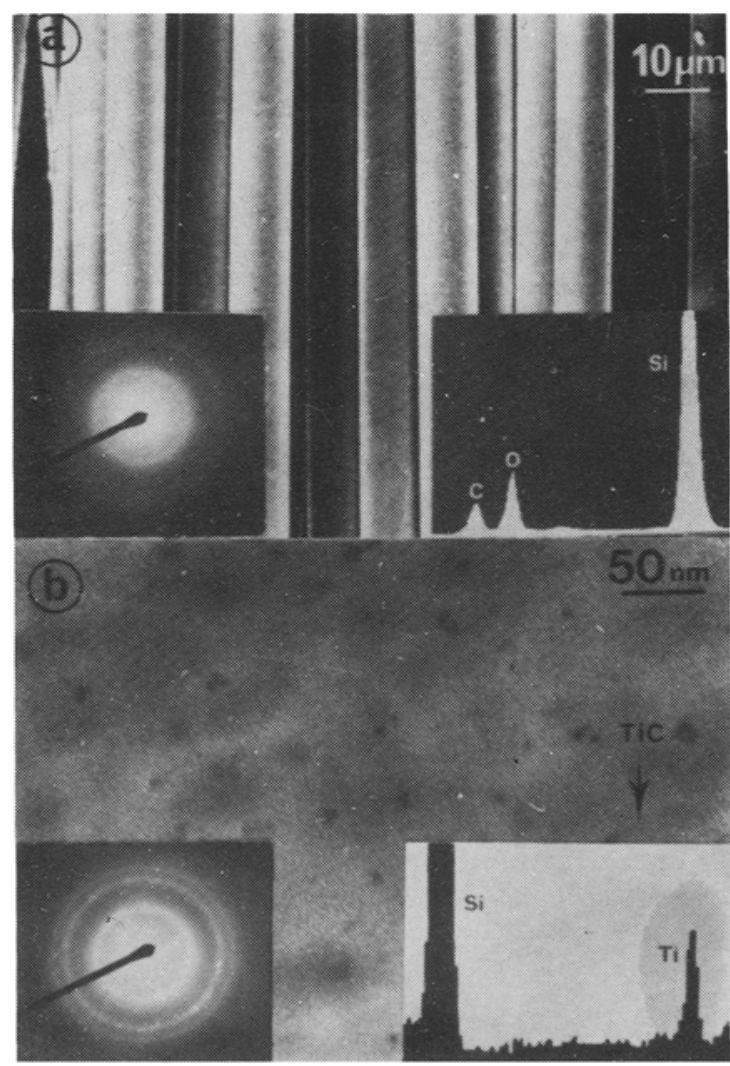

Figure 5. (a) SEM micrographs of SiC (Tyranno) fibres and accompanying EDX analysis and (b) $\mathrm{TiC}$ precipitates in heat treated fibres at $>1300^{\circ} \mathrm{C}$. 


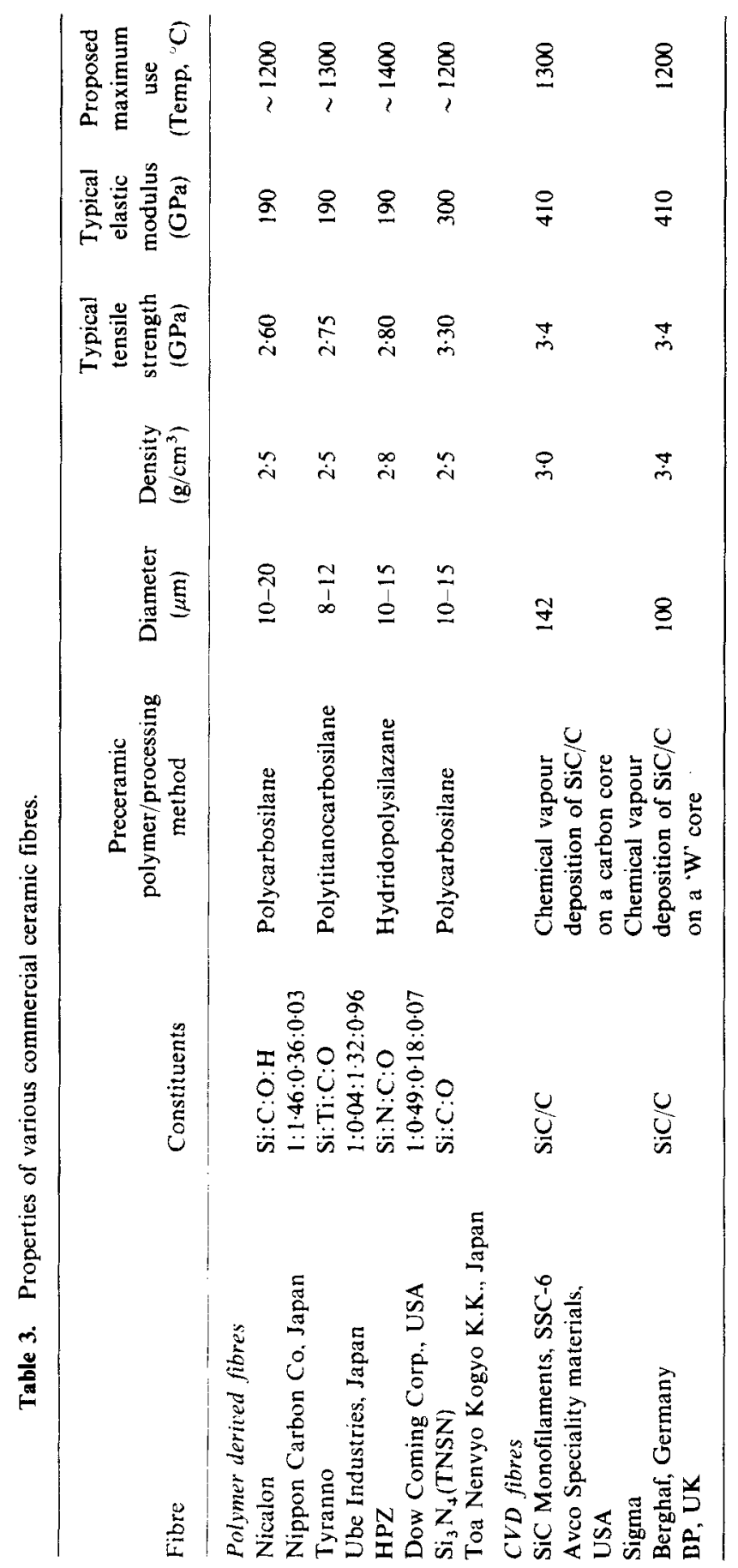




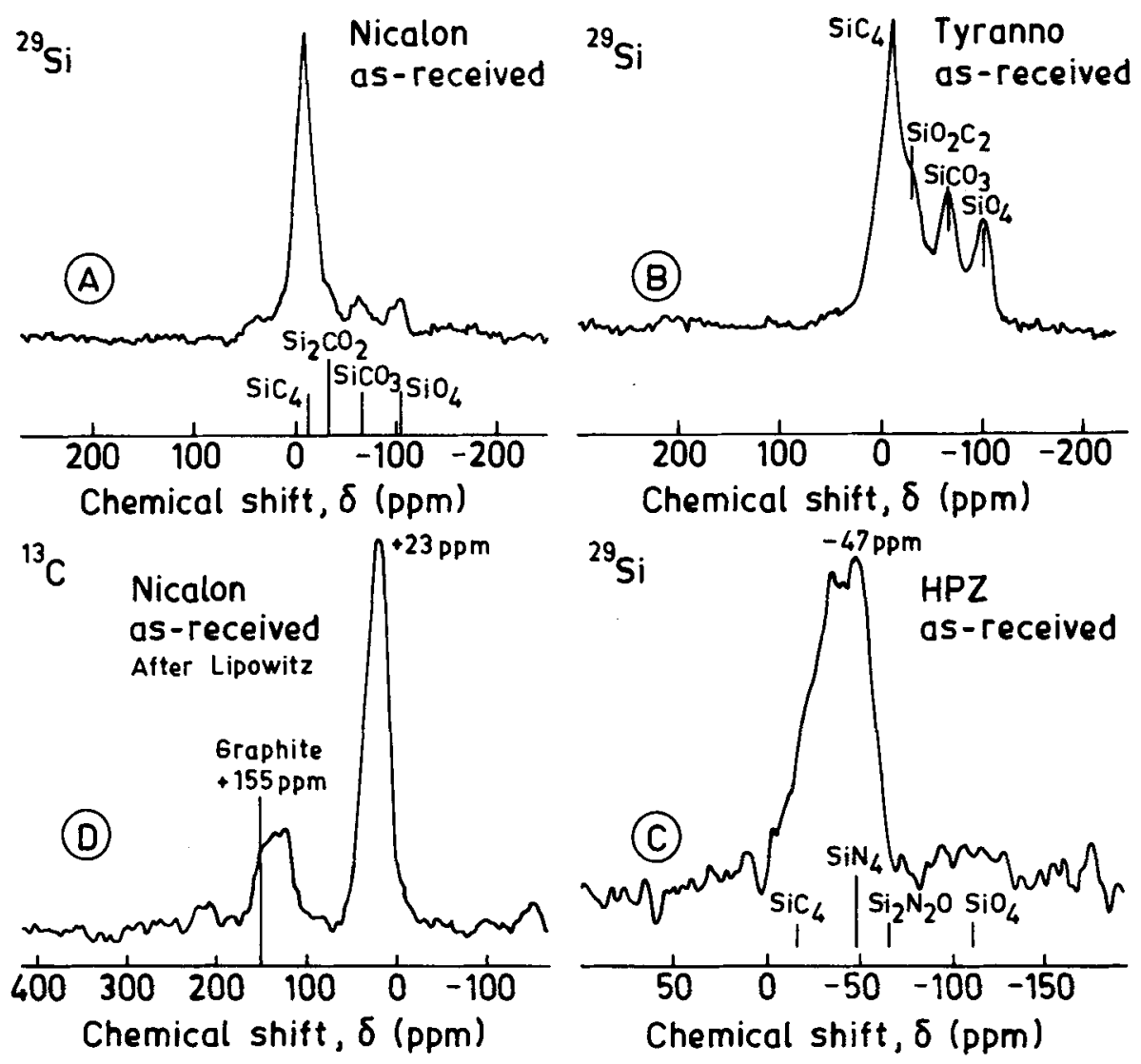

Figure 6. ${ }^{29} \mathrm{Si}$ and ${ }^{13} \mathrm{C}$ MAS-NMR spectra obtained from commercial $\mathrm{SiC}$ and $\mathrm{Si}_{3} \mathrm{~N}_{4}$ fibres.

${ }^{13} \mathrm{C}$ spectrum of Nicalon fibres is taken from Lipowitz's work.

peak, which is attributed to mixed chemical bonding of carbon and oxygen (Porte and Sartre 1989). Further insight about structural details has been obtained using MAS-NMR spectroscopy (Legrow et al 1987; Lipowitz et al 1987; Murthy et al 1989; Taki et al 1989; Lewis et al 1990). ${ }^{29} \mathrm{Si}$ MAS-NMR spectra obtained from as-prepared fibres are shown in figure 6. Nicalon and Tyranno fibres exhibit mixed tetrahedra coordinations with silicon, oxygen and carbon $\left(\mathrm{SiO}_{x} \mathrm{C}_{4-x} ; 0<x<4\right)$; the higher oxygen and titanium dispersion in Tyranno fibres increases the structural disorder (figure 6b). HPZ fibres show a peak at $-47 \mathrm{ppm}$ based on $\mathrm{SiN}_{4}$ coordination with asymmetric broadening towards $\mathrm{SiC}_{4}$ polytypic structure, indicative of mixed coordinations ( $\mathrm{SiN}_{a} \mathrm{C}_{b} \mathrm{O}_{c} ; a+b+c=4$ ) (figure $6 \mathrm{c}$ ).

The excess free carbon which is produced during the course of organic-inorganic transformation is dispersed uniformly within the structure (Yajima et al 1979). Free carbon in the fibre is disorganized, polyaromatic ( $\mathrm{sp}^{2}$ bonded), and turbostratic in nature and is spread over to several nanometers $(\sim 6 \mathrm{~mm})$ in the polyaromatic plane (a-axis) (Lipowitz 1991). The presence of free carbon (as graphite microcrystals) has also been confirmed by several authors (figure 6d) (Day et al 1989; Laffon et al 1989; Maniette and Oberlin 1989). The number of colonies and size keeps growing as the temperature increases and graphite fills the interstices between $\mathrm{SiO}_{2}$ or $\mathrm{SiC}$. Graphite precipitates, besides holding $\mathrm{SiC}$ together, also suppress the growth and coale- 


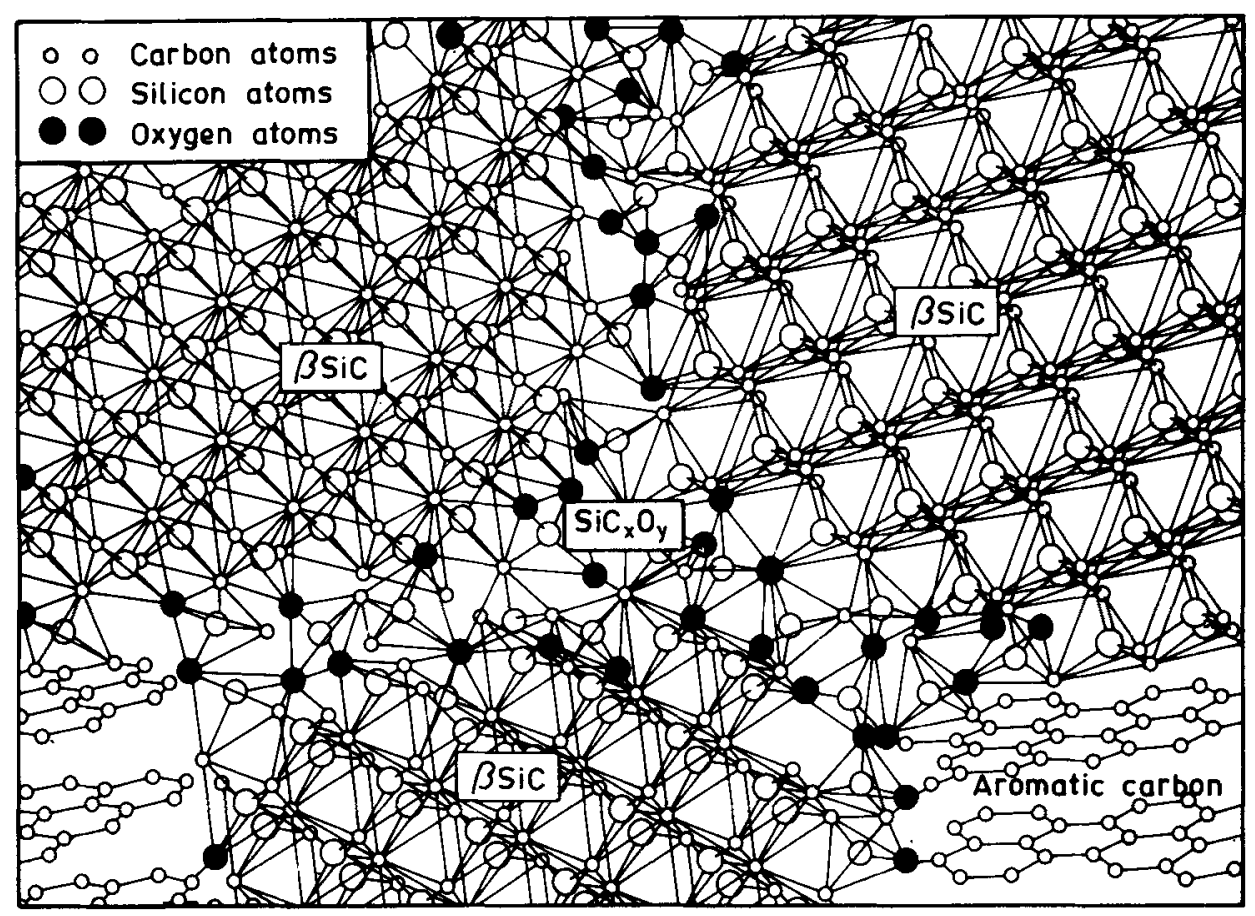

Figure 7. Model microstructure of SiC (Nicalon) fibre. (after Laffon et al 1989).

scence of SiC microcrystals. Based on various structural details, a two-dimensional model has been proposed for Nicalon fibre (Laffon et al 1989) (figure 7). In addition to different phases, a pore phase has also been identified in $\mathrm{Si}-\mathrm{C}-\mathrm{O}$ and $\mathrm{Si}-\mathrm{N}-\mathrm{C}-\mathrm{O}$ fibres. The porosity appears to be globular in shape and the pore size varies depending on pyrolysis temperature (Chaim et al 1988; Lipowitz et al 1990).

\subsection{Microstructural stability and its influence on mechanical properties}

Fibres derived from organic precursors exhibit exceptionally high tensile strength and elastic modulus (table 3; figure 8). The higher tensile properties are attributed to a microcrystalline structure, although the exact relation between the two is not fully understood. However, properties are found to be dependent on the impurities and flaws (internal or surface) created during the spinning process. For instance, the properties of $\mathrm{Si}-\mathrm{C}-\mathrm{O}$ and $\mathrm{Si}-\mathrm{O}-\mathrm{N}-\mathrm{C}$ are controlled by the amount of oxygen present within the fibre (Sawyer et al 1987; Okamura et al 1988a). Oxygen cured Nicalon fibres contain $>10 \mathrm{wt} \%$ oxygen and exhibit inferior properties compared to electron/neutron irradiated fibres with lower oxygen content $(3-4 \%)$. Fast irradiation not only reduces the retained oxygen but also improves the density of the fibre and hence its properties (figure 9) (Matsuzawa et al 1988; Okamura et al 1988a).

The thermal stability of these fibres has been measured by tensile strength retention after annealing in vacuum, argon, nitrogen and air (Mah et al 1984; Simon and Bunsell 1984a; Yamamura et al 1987; Jaskowiak and Dicarlo 1989; Pysher et al 1989; Kim and Moorhead 1991); generally, properties of all the fibres decrease with increase in temperature. High temperature structural degradation of silicon oxycarbide fibres 

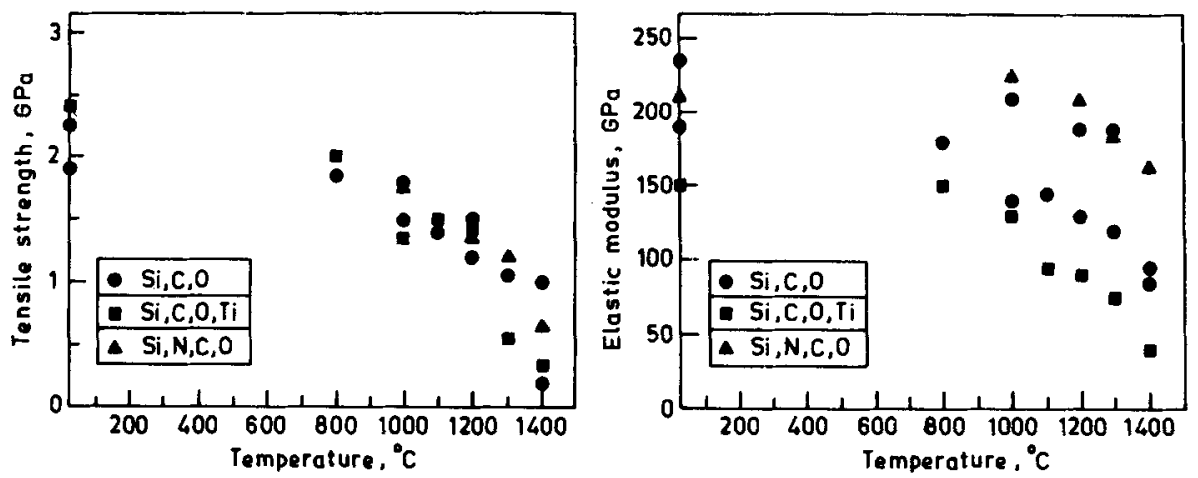

Figure 8. Fast fracture tensile strength and elastic moduli for Nicalon, Tyranno and HPZ fibres (after Lipowitz 1991).
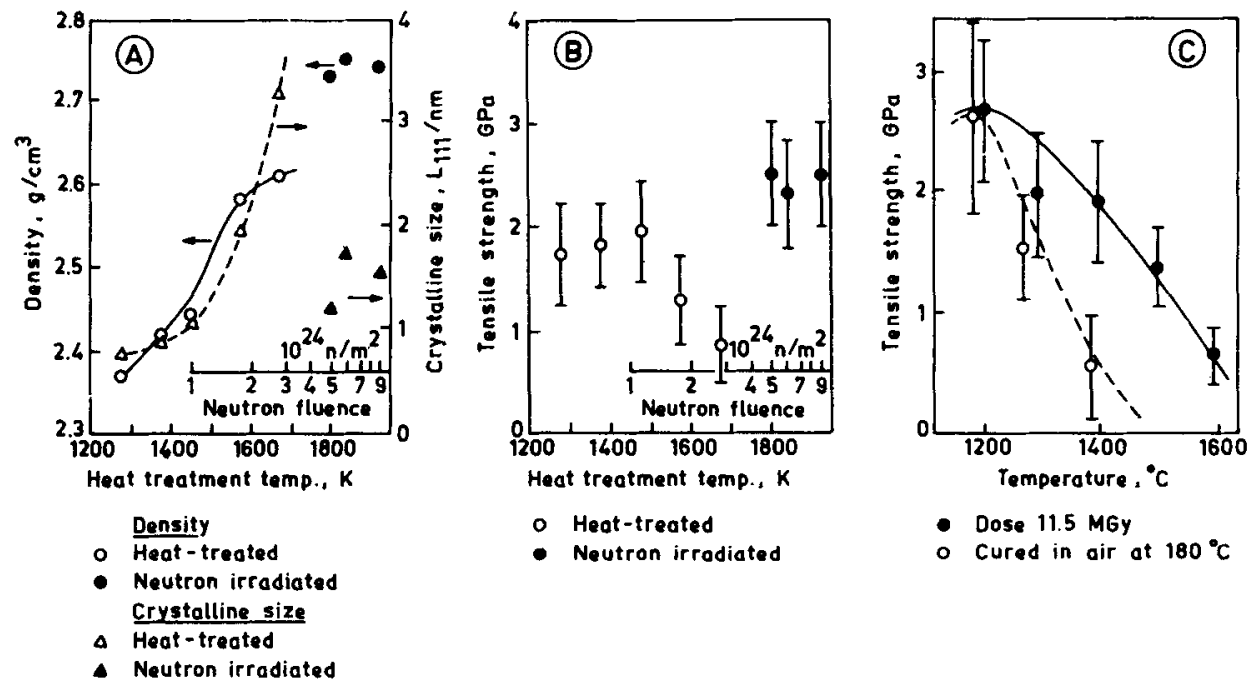

- Neutron irrodiated

- Dose 11.5 MGy

- Cured in air at $180^{\circ} \mathrm{C}$

Figure 9. (A) Density and crystalline size of heat heated and neutron irradiated fibres (Matsuzawa et al 1988), (B) tensile strength of heat-treated, and neutron irradiated fibres (after Matsuzawa et al 1988) and (C) comparison of heat-treated and electron irradiated fibres (after Okamura et al 1988a).

occurs by $\mathrm{CO}$ loss followed by progressive segregation of $\mathrm{C}$ and $\mathrm{O}$ to their respective tetrahedra $\left(\mathrm{SiC}_{4}\right.$ and $\left.\mathrm{SiO}_{4}\right)$ with an accompanying increase in long range order. The ultimate structure is a microcrystalline mixture of $\beta \mathrm{SiC}$ and $\mathrm{SiO}_{2}$ (cristobalite) (Murthy et al 1989). Due to the transition from short range order (nanocrystalline) to long range order $(\beta \mathrm{SiC})$, fibre fracture changes from glassy to granular. In vacuum or inert atmospheres oxygen is lost as $\mathrm{SiO}$ and $\mathrm{CO}$, leaving microporous $\beta \mathrm{SiC}$ crystalline fibres of low strength $(<0.4 \mathrm{GPa})$. In nitrogen atmosphere, the surface undergoes nitridation and the out-diffusion of gases becomes sluggish. In Tyranno, uniformly dispersed titanium reacts with free carbon and precipitates as $\mathrm{TiC}$ (figure 5). Further, creep properties of the fibres are also controlled by the change that occurs in the fibre viz. $\mathrm{SiC}$ grain growth and $\mathrm{SiO}_{2}, \mathrm{SiO}$ and $\mathrm{CO}$ formation (Simon and Bunsell 1984b). 


\section{SiC monofilaments via chemical vapour deposition}

In the early stages of development, $\mathrm{SiC}$ monofilaments were produced by deposition of $\mathrm{SiC}$ onto a tungsten core $(\sim 12 \mu \mathrm{m}$ in diam.). In the as-prepared state, these fibres possess high tensile strength $(3.45 \mathrm{GPa})$, however, the strength rapidly decreases as temperature approaches $1000^{\circ} \mathrm{C}$. The strength degradation is mainly attributed to the reaction between tungsten and deposited $\mathrm{SiC}$. Although, the reaction between tungsten core and the substrate is limited during deposition of $\mathrm{SiC}$ sheath, the reaction layer $\left(\mathrm{W}_{5} \mathrm{Si}_{3}\right.$ and $\left.\mathrm{W}_{2} \mathrm{C}\right)$ thickness increases by consuming all the tungsten core and induces brittleness to the fibre (Crane and Krukonis 1975; Wawner 1988). To overcome the detrimental reaction between the core and the $\mathrm{SiC}$ substrate, tungsten was later replaced by carbon fibre. These improved fibres with ' $C$ ' core are produced by AVCO speciality materials, USA and are available for preparation of various composite materials (Prewo and Brennan 1980; Anderson and Warren 1984; Buljan and Sarin 1987; Jansson et al 1991; Scott et al 1991).

\subsection{Production}

A vertical glass chamber with mercury seals at both ends is used with inlet and exit ports for introducing and removing reactant gases and products respectively (figure 10). Carbon fibre is pulled continuously through the chamber and heated electrically with DC current. Monofilaments are produced by thermal decomposition of various silanes (methyl trichlorosilane and methyldichlorosilane), hydrogen, propane and argon. The kinetics of $\mathrm{SiC}$ deposition are complicated and sensitive to deposition

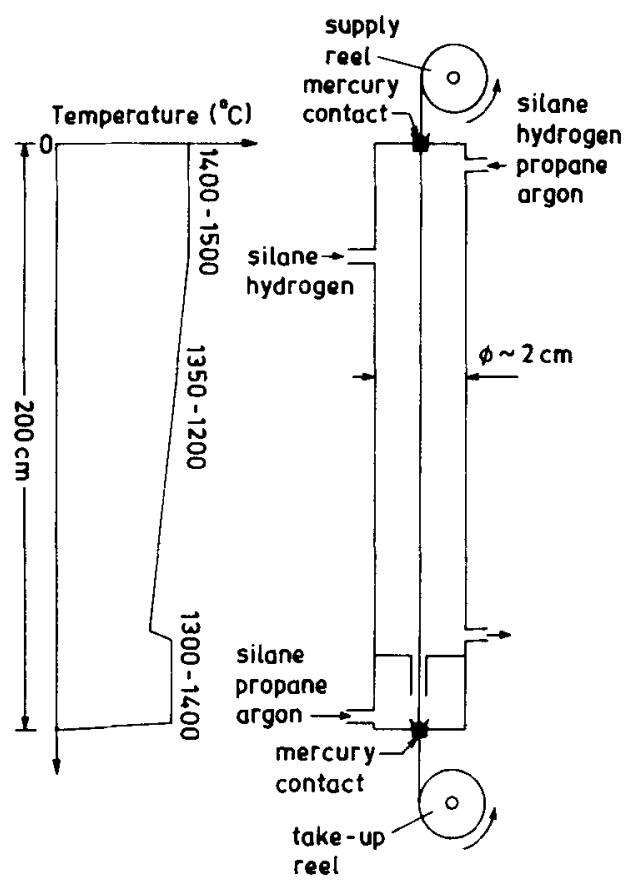

Figure 10. Schematic diagram of a reactor used to produce SiC monofilaments (Martineau et al 1984). 
pressure, flow, temperature, etc. While it is possible to obtain single phase of $\mathrm{SiC}$, sometimes, traces of carbon and silicon are also deposited due to changes in the proportion of gas mixtures (Chin et al 1977; Kingon et al 1983; Martineau et al 1984). Additionally, variation of fibre resistance along the reactor length as $\mathrm{SiC}$ is being deposited, this generates a temperature gradient (figure 10) and influences the deposition and microstructure.

\subsection{Microstructure}

AVCO SiC monofilaments produced via CVD are large in diameter $(\sim 142 \mu \mathrm{m})$. Initially, a pyrolitic graphite $(\sim 1 \mu \mathrm{m})$ is deposited onto the carbon core of $33 \mu \mathrm{m}$ (a) to improve the surface for $\mathrm{SiC}$ deposition and (b) to make the carbon fibre diameter uniform so that constant resistance is obtained during heating of the substrate. Following pyrolytic graphite, a sheath of $\mathrm{SiC}$ is deposited in a columnar crystal morphology (figure 11). The sheath consists of mainly $\beta \mathrm{SiC}$ grains extending in the radial direction with $\langle 111\rangle$ preferred orientation (Wawner et al 1983; Nutt and Wawner 1985). The columnar grains within the sheath vary in size (40-50 nm near the substrate and $90-100 \mathrm{~nm}$ at the surface). Such a variation in grain size is attributed to the temperature difference within the production chamber. High supersaturation generally results in a high nucleation density (i.e. fine grains), whereas low saturation gives rise to coarse grain structure (Wawner et al 1983). MAS-NMR studies on the monofilaments revealed that the $\mathrm{SiC}$ is mainly $\beta \mathrm{SiC} \mathrm{(3c)} \mathrm{with} \mathrm{other} \mathrm{polytypic} \mathrm{forms}$ such as 6H and 15R (figure 11) (Lewis et al 1990; Murthy et al 1990). Besides SiC, small amounts of free silicon were also detected in the microstructure (Brun and Borom 1989). Further, the fibre is coated with twin layers of amorphous carbon (by varying the ratio of $\mathrm{SiC}$ to $\mathrm{C}$ ) towards the surface and the thickness can be varied to meet specific applications. The outer carbon-rich layer is claimed to heal microcracks on the $\mathrm{SiC}$ and also acts as a low-cohesion layer at the fibre-matrix interface in ceramic matrix composites. Similarly, $\mathrm{Si}_{3} \mathrm{~N}_{4}$ fibres using $C$ or $W$ core can be produced using $\mathrm{Si}_{4} \mathrm{Cl}$ and $\mathrm{NH}_{3}$ reactant combination.

\subsection{Properties}

In the as-prepared condition, fibres display very high tensile strength ( $\sim 4 \mathrm{GPa})$ and tensile modulus ( $\sim 400 \mathrm{GPa}$ ) (Siemers et al 1988). However, tensile strength decreases drastically beyond $1200^{\circ} \mathrm{C}$, both in oxidative and protective atmospheres (figure 12) (Dicarlo 1985). The poor performance of monofilaments at elevated temperatures is attributed to residual silicon which coexists with $\beta$ SiC (Dicarlo 1986; Brun and Borom 1989). At still higher temperatures $\left(>1400^{\circ} \mathrm{C}\right)$, fibres degrade because of $\mathrm{SiO}$, $\mathrm{CO}$ evaluation coupled with precipitation of impurities present within the fibre (Johnson et al 1988).

The creep properties were also found to be poor due to the presence of free silicon (Dicarlo 1985, 1986). A prior thermal heat-treatment above $1400^{\circ} \mathrm{C}$ was suggested to improve the creep properties of CVD fibres. It is believed that free silicon present in the grain boundaries will evaporate as $\mathrm{SiO}$, thereby increasing viscosity of the grain boundary film and improving the resistance to grain boundary sliding (Dicarlo 1986).

Although $\mathrm{SiC}$ monofilaments are stable up to $1200^{\circ} \mathrm{C}$, the large fibre diameter and 

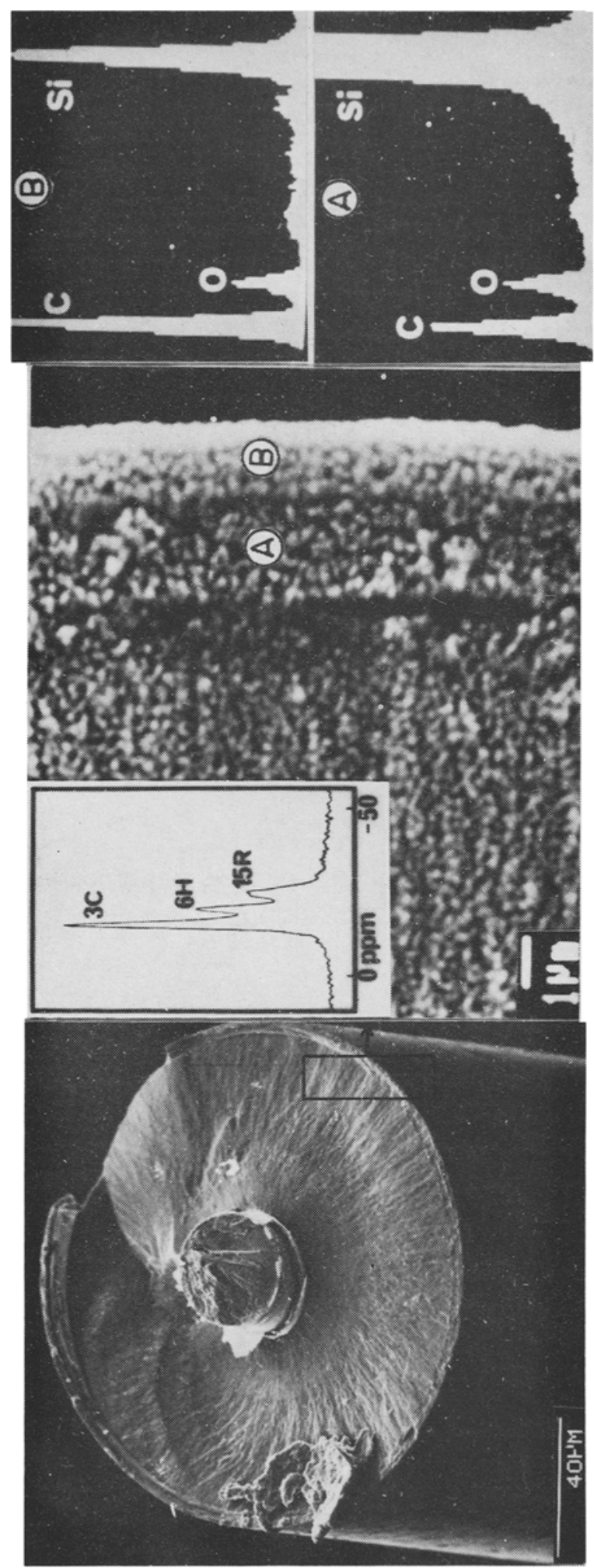

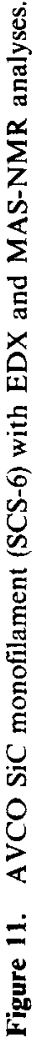



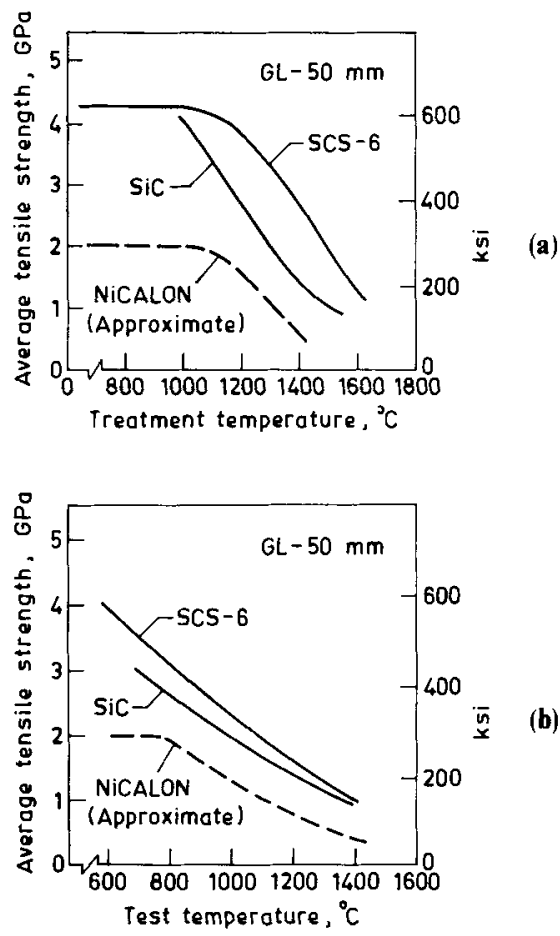

Figure 12. Strength retention of AVCO SiC fibre in (a) argon/nitrogen and (b) oxygen environments (after 15 min exposure) (after Dicarlo 1985).

poor creep resistance are major limitations during fabrication and performance of $\mathrm{CMCs}$ respectively.

\section{SiC fibres by other methods}

\subsection{Controlled in situ reaction of carbon (fibre) and silicon}

Attempts have been made to convert carbon fibres into silicon carbide fibres by depositing free silicon (via CVD) on to a carbon fibre and controlling the in situ reaction between $\mathrm{Si}$ and $\mathrm{C}$. Two mechanisms are proposed for conversion of $\mathrm{C}+\mathrm{Si}$ to $\mathrm{SiC}$ (Pampuch et al 1987). (a) Formation of a $\mathrm{SiC}$ reaction layer on the $\mathrm{C}$ fibre surface and further growth of $\mathrm{SiC}$ via out-diffusion of carbon through the reaction layer to react with outside $\mathrm{Si}$. The diffusion of $\mathrm{C}$ through $\mathrm{SiC}$ reaction layer is much faster than in-diffusion of $\mathrm{Si}$ through $\mathrm{SiC}$ shell and hence the reaction is expected to be self-sustaining and (b) $\mathrm{SiC}$ precipitation from the supersaturated liquid of $\mathrm{C}$ in liquid silicon. This mechanism seems to be faster compared to the former because of higher diffusivity in the liquid phase. $\mathrm{SiC}$ which has initially formed is porous in nature (figure 13) and encourages the out-diffusion of $\mathrm{C}$ through the shell. The solution formation of $\mathrm{C}$ in $\mathrm{Si}$ is endothermic in nature while precipitation of $\mathrm{SiC}$ from $\mathrm{C}+\mathrm{Si}$ solution is exothermic. The temperature at the $\mathrm{C}+\mathrm{Si} / \mathrm{SiC}$ interface oscillates resulting in successive zones of poor and rich carbon regions with reference to $C$. Hence. 


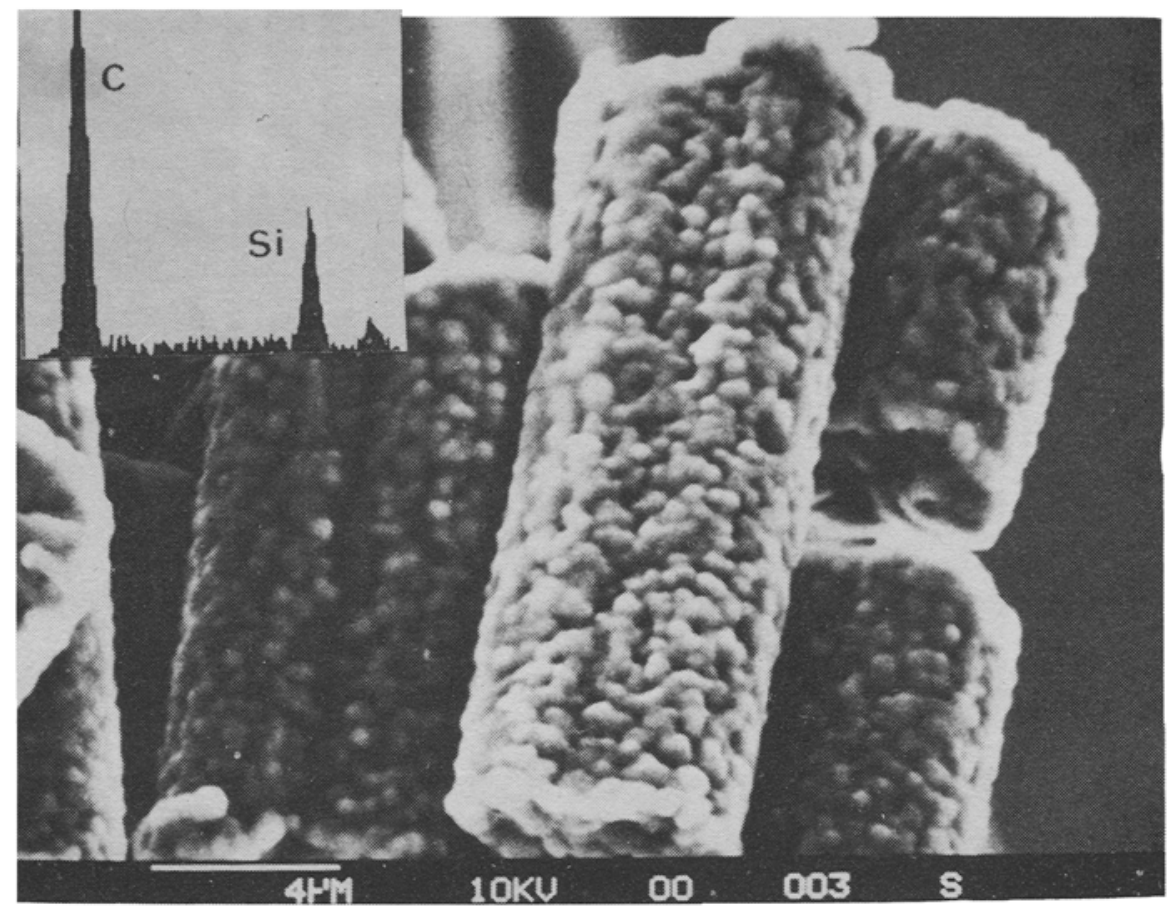

Figure 13. SiC fibres obtained via in situ reaction of carbon fibres and silicon.

control over the overall reaction kinetics and densification of $\mathrm{SiC}$ fibre to near theoretical value are essential for successful production of $\mathrm{SiC}$ fibres.

\subsection{Extrusion of fine ceramic powders followed by sintering}

Fine ceramic powder (submicron or nanometer size) is mixed with appropriate sintering aids and binder and the admixture is extruded through a nozzle. Stoichiometric or near-stoichiometric powders used in this method are expected to give better properties, especially at higher temperatures $\left(>1200^{\circ} \mathrm{C}\right)$. The extruded filament is subsequently sintered at elevated temperatures to obtain desired mechanical properties. The major limitation is the diameter of the fibre, which is larger $(\sim 70 \mu \mathrm{m})$ as compared to polymer derived fibres. Residual porosity is a strength-limiting factor in these fibres (figure 14) and attempts are under way to improve the fibre strength.

\section{New developments}

Oxygen-induced degradation of fibre structure and fibre-matrix interface microstructure is a major obstacle in the development of FRCMC. To improve the stability of existing fibres and interfaces, presynthesized multiple surface coatings of varying thicknesses $(0 \cdot 25-2 \cdot 0 \mu \mathrm{m})$ are given on as-prepared fibres. The primary layer is a layered structure (Van der wall type) with low-cohesion and low shear stress $(\tau)$ coupled with stability and non-reactivity at elevated temperatures. The second layer 


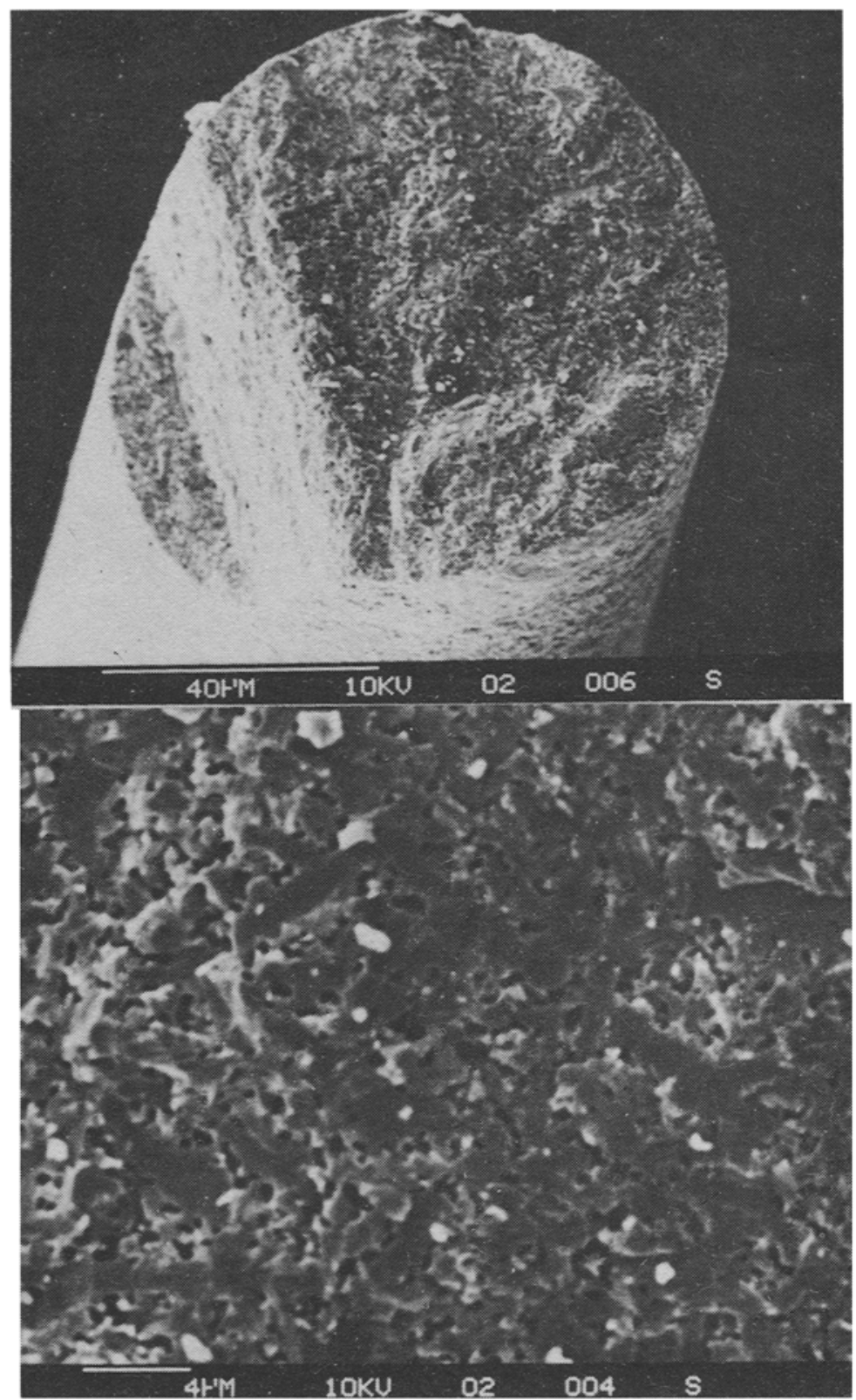

Figure 14. $\mathrm{SiC}$ fibre obtained by extrusion of fine powder followed by high temperature sintering; in a magnified view, residual porosity is clearly visible.

is essentially a refractory coating to protect the low-cohesion layer and fibre during processing and performance: Sometimes, a third coating may be necessary if the second layer is incompatible with matrix chemistry. Carbon or boron nitride and $\mathrm{SiC}$ are emerging as the potential coating materials for primary and secondary layers respectively (Bender et al 1986; Lowden et al 1988). A combination of porous SiC 
(CVD) followed by $\mathrm{Ta}_{2} \mathrm{O}_{5} / \mathrm{Nb}_{2} \mathrm{O}_{5}$ (sol-gel) has also proved to be successful in deflecting the crack efficiently at the fibre-matrix interfaces (Sheppard 1992).

Currently available yarn-based, non-crystalline $\mathrm{SiC}$ and $\mathrm{Si}_{3} \mathrm{~N}_{4}$ fibres exhibit microstructural instabilities beyond $1200^{\circ} \mathrm{C}$, with poor mechanical properties. Therefore, there is an immediate need for the development of fibres which can retain strength up to $1400^{\circ} \mathrm{C}$. MERC, Dow corning and Carborundum (USA) are trying to develop a new class of silicon carbide fibres which are expected to exhibit improved properties up to $1600^{\circ} \mathrm{C}$. Several Japanese research organizations have also joined in the effort by developing $\mathrm{B}-\mathrm{N}$ and $\mathrm{Si}-\mathrm{B}-\mathrm{N}$ fibres, which are also targeted for CMC applications (Sheppard 1992).

\section{Summary}

(I) Although many organosilicon polymers have been explored for the development of $\mathrm{SiC}$ and $\mathrm{Si}_{3} \mathrm{~N}_{4}$ fibres, only polycarbosilane, polytitanocarbosilane and polysilazane have emerged as potential starting materials for the production of continuous silicon (oxy) carbide (Nicalon), Si-Ti-C-O (Tyranno) and silicon (oxycarbo) nitride (HPZ) fibres respectively. Of these, silicon (oxy) carbide is the most extensively studied system.

(II) Both, curing and pyrolysis play an important role in the evolution of microstructure and mechanical properties of polymer derived fibres. In these fibres, polymerto-ceramic conversion takes place in various steps; with progressive structural readjustments, fibre gains strength up to a critical point and beyond, strength decreases drastically due to coarsening of the structure and $\mathrm{CO}$ gas evolution.

(III) All the polymer derived ceramic fibres exhibit mixed tetrahedra coordinations with $\mathrm{Si}, \mathrm{O}, \mathrm{C}$ and $\mathrm{N}$. Excess free carbon in these fibres is dispersed uniformly in the microstructure as graphite microcrystallites. In addition to different phases present, a pore phase has also been identified.

(IV) Fibres from organic precursors exhibit very high tensile properties. However, the stability (structural and mechanical) of these fibres is poor beyond $1000^{\circ} \mathrm{C}$. At higher temperatures, the mixed $\mathrm{C}$ and $\mathrm{O}$ coordinations are progressively replaced by segregated $\mathrm{SiC}_{4}$ and $\mathrm{SiO}_{4}$ tetrahedra. In vacuum or inert atmosphere, oxygen within the fibre reacts with $\mathrm{Si}$ and $\mathrm{C}$ and escapes as $\mathrm{SiO}$ and $\mathrm{CO}$ respectively, leaving behind a microporous crystalline fibre.

(V) SiC monofilaments prepared via chemical vapour deposition are larger in diameter $(\sim 142 \mu \mathrm{m})$ and possess good mechanical properties. However, the performance of these fibres is limited up to $\sim 1200^{\circ} \mathrm{C}$ due to residual silica present along with $\beta \mathrm{SiC}$. Traces of silica affect the creep properties and a prior thermal heat-treatment $>1400^{\circ} \mathrm{C}$ believed to improve the creep resistance.

(VI) Attempts have also been made to produce SiC fibres by other methods such as (i) conversion of carbon fibres to $\mathrm{SiC}$, via reaction $\mathrm{C}$ and $\mathrm{Si}$ (deposited on the surface) and (ii) extrusion of fine powders. However, these methods are yet to be perfected.

(VII) Presently available non-oxide ceramic fibres have a limited temperature capability (up to $1000^{\circ} \mathrm{C}$ ) and there is a need to develop fibres which can retain good strength above $1400^{\circ} \mathrm{C}$. On the one hand, currently available yarn base fibre performance is extended by giving multi-layer coatings and on the other hand, new non-oxide fibres are being developed for high-temperature applications. 


\section{Acknowledgement}

The author would like to thank Dr G S Murty and Dr S Sangal for their suggestions in preparing the manuscript.

\section{References}

Anderson C N and Warren R 1984 Composites 1516

Baney R H and Gaul Jr J A 1982 US patent 4310651

Baney R H 1984 Ultrastructure processing of ceramics, (eds) L L Hench and D R Ulrich (New York: John Wiley and Sons) p. 235

Bender B, Shadwell D, Bulik C, Incorvati L and Lewis D 1986 Am. Ceram. Soc. Bull. 65363

Blum Y D, Schwartz K B and Laine R M 1989 J. Mater. Sci. 241707

Brun M K and Borom M P 1989 J. Am. Ceram. Soc. 721993

Buljan S T and Sarin V K 1987 Composites 1899

Cao H C, Bischoff E, Sbaizero O, Rühle M, Evans A G, Marshall D B and Brennan J J $1990 \mathrm{~J} . \mathrm{Am}$. Ceram. Soc. 73169 !

Carlsson D J, Cooney J D, Gauthier S and Worsfold D J 1990 J. Am. Ceram. Soc. 73237

Chantrell P G and Popper P 1965 Inorganic polymer and ceramics: Special ceramics 4 (ed.) P Popper (New York: Academic Press) p. 87

Chaim R, Heuer A H and Chen R T 1988 J. Am. Ceram. Soc. 71960

Chin J, Gantzel P K and Hudson R G 1977 Thin Solid Films 4057

Crane R L and Krukonis V J 1975 Am. Ceram. Soc. Bull. 54184

Day R J, Piddock V, Taylor R, Young R J and Zakikhani M 1989 J. Mater. Sci. 242898

Dicarlo J A 1985 J. Metals 3744

Dicarlo J A 1986 J. Mater. Sci. 21217

Dicarlo J A 1989 Adv. Mater. Processes 13541

Evans A G $1990 \mathrm{~J}$. Am. Ceram. Soc. 73187

Fritz G, Grobe J and Kummer D 1965 Adv. Inorg. Chem. Radiochem. 7349

Hasegawa Y, Iimura M and Yajima S $1980 \mathrm{~J}$. Mater. Sci. 15720

Hasegawa Y and Okamura K 1983 J. Mater. Sci. 183633

Hasegawa Y and Okamura K 1986 J. Mater. Sci. 21321

Hasegawa Y 1989 J. Mater. Sci. 241177

Ichikawa H, Machino F, Mitsuno S, Ishikawa T, Okamura K and Hasegawa Y 1986 J. Mater. Sci. 214352

Ichikawa H, Teranishi $H$ and Ishikawa T 1987 J. Mater. Sci. Lett. 6420

Jansson S, Deve H E and Evans A G 1991 Metall. Trans. A22 2975

Jaskowiak M H and Dicarlo J A 1989 J. Am. Ceram. Soc. 72192

Johnson S M, Brittain R D, Lamoreaux R H and Rowcliffe D J 1988 J. Am. Ceram. Soc. 71 C132

Kim H and Moorhead A 1991 J. Am. Ceram. Soc. 74666

Kingon A I, Lutz L J and Davis R J $1983 \mathrm{~J}$. Am. Ceram. Soc. 66551

Laffon C, Flank A M, Lagarde P, Laridjani M, Hegege R, Olry P, Cotteret J, Dixmier J, Miquel J L, Hommel H and Legrand A P 1989 J. Mater. Sci. 241503

Legrow G E, Lim T F, Lipowitz J and Reaoch R S 1987 Am. Ceram. Soc. Bull. 66363

Lewis M H, Dupree R, Murthy V S R and Smith M E 1990 Solid-solid-state NMR abstracts, (Coventry, UK: Warwick University)

Lipowitz J, Freeman H A, Chen R T and Prack E R 1987 Adv. Ceram. Mater. 2121

Lipowitz J, Rabe J A, Frevel L K and Miller R L 1990 J. Mater. Sci. 252118

Lipowitz J 1991 Am. Ceram. Soc. Bull. 701888

Lowden R A, Stinton D P and Besmann T M 1988 Whisker and fibre toughened ceramics (eds) R A Bradley, D E Clark, D C Larsen and J O Skiegler (Cleaveland: American Society of Metals) p. 253

Macey C J, Lehman R L and Moore R L 1984 Scanning electron microscopy (Chicago: SEM Inc., AMF O' Hare) Vol. IV, p. 1643

Mah T, Mecht N L, McCullum D E, Hoenigman J R, Kim H M, Katz A P and Lipsitt H A $1984 \mathrm{~J}$. Mater. Sci. 191191

Maniette Y and Oberlin A 1989 J. Mater. Sci. 243361 
Martineau P, Lahaye M, Pailler R. Naslain R, Couzi M and Cruege F 1984 J. Mater. Sci. 192731

Matsuzawa T, Okamura K and Sato M 1988 Proceedings of MRS Inter. Conf. on Adv. Materials. Tokyo, Japan

Mazdiyasni K S, West R and David L. D 1978 J. Am. Ceram. Soc. 61504

Morley J G 1987 High performance fibre composites (London: Academic Press) p. 51

Murthy V S R, Lewis M H, Smith M E and Dupree R 1989 Mater. Lett. 8263

Murthy V S R, Pharaoh M W and Lewis M H 1990 New materials and their applications (ed.) S Burnay (Bristol: Institute of Physics) paper 5C

Nutt S R and Wawner Jr. F E 1985 J. Mater. Sci. 201953

Okamura K, Sato M and Hasegawa Y 1985 Proceedings of 5 th Inter. Conf. on Comp. Materials, San Diego, C A, USA (eds) E C Harrigan Jr., J Strife and A K Dkhingra, (USA: American Ceramic Society) p. 535

Okamura K, Sato M, Seguchi T and Kawanishi S 1987a Sintering 1987 (eds) S Somiya, M Shimada, M Yoshimura and R Watanabe (Amsterdam: Elsevier) Vol. 1, p. 102

Okamura K, Sato M and Hasegawa Y 1987b High tech. ceramics (ed.) P Vincenzini (Amsterdam: Elsevier Science Pub.) p. 747

Okamura K 1987 Composites 18107

Okamura K, Sato M, Matsuzawa T, Seguchi T and Kawanishi S 1988a Ceram. Engg. Sci. Proc. 9909

Okamura K, Sato M, Matsuzawa T and Hasegawa $Y 1988 \mathrm{~b}$ Ultrastructure processing of advanced ceramics (eds) J D Mackenzie and D R Ulrich (New York: John Wiley and Sons) p. 501

Pampuch R, Biazoskorski J and Walasek E 1987 High tech ceramics (ed.) P Vincenzini (Amsterdam: Elsevier Science Pub.) p. 217

Penn B G, Ledbetter F E, Clemons J M and Daniels J G 1982 J. Appl. Poly. Sci. 273751

Popper P 1967 New electrical ceramic and inorganic polymers (UK: British. Ceram. Res. ASSH) p. 57

Porte L and Sartre A 1989 J. Mater. Sci. 29271

Prewo K M and Brennan J J 1980 J. Mater. Sci. 15463

Pysher D J, Goretta K C. Hodder Jr. R S and Tressler R E 1989 J. Am. Ceram. Soc. 72284

Rice R W 1983 Am. Ceram. Soc. Bull. 62889

Sasaki Y, Nishina Y. Sato M and Okamura K 1987 J. Mater. Sci. 22443

Sawyer L C, Jamieson M, Brikowski D. Ishaq Haider M and Chen R T 1987 J. Am. Ceram. Soc. 70798

Schilling Jr. C L, Wesson J P and Williams T C 1983 Am. Ceram. Soc. Bull. 62 p. 912

Schmidt W R, Sukumar V, Hurley Jr. W J, Garcia R, Doremus R H, Interrante L V and Renlund G M 1990 J. Am. Ceram. Soc. 732412

Scott V D, Trumper R L and Yang M 1991 Comp. Sci. Tech. 42 p. 251

Seyferth D and Wiseman G H 1984 Ultrastructure processing of ceramics, glasses and composites (eds) L L Hench and D R Ulrich (New York: John Wiley and Sons) p. 265

Sheppard L M 1992 Am. Ceram. Soc. Bull. 71617

Siemers P A, Mehan R L and Moran H 1988 J. Mater. Sci. 231329

Simon G and Bunsell A R 1984a J. Mater. Sci. 193649

Simon G and Bunsell A R 1984b J. Mater. Sci. 193658

Song Y C, Hasegawa Y, Yang S J and Sato M 1988 J. Mater. Sci. 231911

Soraru G D, Babonneau F and Mackenzie J D 1990 J. Mater. Sci. 253886

Taki T, Okamura K, Sato M, Seguchi T and Kawanishi S 1988 J. Mater. Sci. Lett. 7209

Taki T, Okamura K and Sato M 1989 J. Mater. Sci. 241263

Taki T, Inui M, Okamura K and Sato M 1989 J. Mater. Sci. Lett. 8918

Verbeek W 1974 US Patent 3853567

Wawner Jr. F W, Teng A Y and Nutt S R 1983 SAMPE Q. 1439

Wawner Jr. F W 1988 Composite materials series 2 (ed.) A R Bunsell (New York: Elsevier) p. 371

Wei G C, Kennedy C. R and Harris L A 1984 Am. Ceram. Soc. Bull. 631054

West R, David L D, Djurovich P I and Yu N 1983 Am. Ceram. Soc. Bull. 62899

West R 1984 Ultrastructure processing of ceramics, glasses and composites (eds) L L Hench and D R Ulrich (New York: John Wiley) p. 235

Wills R R, Markle R A and Mukherjee S P 1983 Am. Ceram. Soc. Bull. 62904

Wynne K J and Rice R W 1984 Ann. Rev. Mater. Sci. 14297

Yajima S, Hayashi J and Omori 1975 Chem. Lett. p. 931

Yajima S, Okamura K, Hayashi J and Omori M 1976a J. Am. Ceram. Soc. 59324

Yajima S, Liaw C, Omori M and Hayashi J 1976b Chem. Lett. p. 435

Yajima S, Omori M, Hayashi J, Okamura K, Matsuzawa T and Liaw C 1976c Chem. Lett. p. 551 
Yajima S, Hayashi L and Okamura K 1977a Chem. Lett. p. 521

Yajima S, Hayashi J and Okamura K 1977b Nature 266521

Yajima S, Hasegawa Y, Hayashi J and Iimura M 1978a J. Mater. Sci. 132569

Yajima S, Hasegawa Y, Okamura K and Matsuzawa T 1978b Nature 273525

Yajima S, Okamura K, Matsuzawa J, Hasegawa Y and Shishido T 1979 Nature 279706

Yajima S 1980 Philos. Trans. Roy. Soc. (London) A294 419

Yajima S, Iwai T, Yamamura T, Okamura K and Hasegawa T 1981 J. Mater. Sci. 161349

Yajima S 1983 Am. Ceram. Soc. Bull. 62893

Yajima S 1985 Handbook of composites vol. 1 - short fibres, (eds.) W Watt and B V Perov (Amsterdam: Elsevier Science Pub.) p. 201

Yamamura T 1984 Polymer preprints 25 no. 3 p. 8

Yamamura T, Hurushima T, Kimoto M, Ishikawa T, Shibuya M and Iwai T 1987 High tech ceramics (ed.) P Vincenzini (Amsterdam: Elsevier Science Pub.) p. 737

Yamamura T, Ishikawa T, Shibuya M, Hisayuki T and Okamura K 1988 J. Mater. Sci. 232589

Yokoyama Y, Nanba T, Yasui T, Kaya N, Maeshima T and Isoda T 1991 J. Am. Ceram. Soc. 74654

Zhang Z F, Babonneau F, Laine R M, Mu Y, Harrod J F and Rahn J A 1991 J. Am.Ceram. Soc. 74670 